\title{
BLACK MARKET AND OFFICIAL EXCHANGE RATES: \\ LONG-RUN EQUILIBRIUM \\ AND SHORT-RUN DYNAMICS
}

\author{
Guglielmo Maria Caporale \\ Brunel University \\ Mario Cerrato \\ London Metropolitan University
}

March 2005

\begin{abstract}
This paper provides further empirical results on the relationship between black market and official exchange rates in six emerging economies (Iran, India, Indonesia, Korea, Pakistan, and Thailand). First, it applies both time series techniques and heterogeneous panel methods to test for the existence of a long-run relation between these two types of exchange rates. Second, it tests formally the validity of the proportionality restriction implying a constant black-market premium. Third, in addition to the long-run equilibrium, it also analyses the short-run dynamic responses of both markets to shocks. Evidence of market inefficiency and incomplete (or longlived) reversion to long-run equilibrium is found. This implies that financial managers can only partially reduce the exchange rate risk, whilst monetary authorities can effectively pursue their policy objectives by imposing foreign exchange or direct controls.
\end{abstract}

Keywords: Black Market and Official Exchange Rates, Panel Cointegration, Impulse Response Functions

\section{JEL Classification: C23, F31}

Corresponding author: Professor Guglielmo Maria Caporale, Brunel Business School, Brunel University, Uxbridge, Middlesex UB8 3PH, UK. Tel.: +44 (0) 1895 2667137. Fax: +44 (0)1895269770.

Email: Guglielmo-Maria.Caporale@brunel.ac.uk 


\section{Introduction}

Black markets for foreign currency develop mainly as a result of government restrictions on capital outflows. These induce domestic residents to seek alternative sources of foreign currency. Its supply generally comes from domestic residents connected with the tourist industry, while demand originates mainly from residents travelling abroad on holiday or to study. Since demand for foreign currency normally exceeds supply, suppliers are able to charge a higher price than the official rate. The difference between the black market (or parallel) exchange rate and the official rate is known as the black-market premium.

As argued in Kiguel and O'Connell (1995), a significant spread between black market and official rate may be a signal of macroeconomics misalignments, and consequently central banks will often intervene in the official market to eliminate the spread - hence the importance of investigating whether there exists a long-run relationship between black market and official exchange rates. This is also crucial to establishing whether or not the black market processes information efficiently, i.e. whether investors use information contained in the black market rate to predict movements in the official rate. The implications are extremely important not only for policy-makers but also for financial managers investing in emerging markets and managing the exchange rate risk. In addition to the long-run equilibrium, it is also interesting to analyse the short-run speed of adjustment of the two types of exchange rates in response to external shocks.

In this paper, we use both time series and heterogeneous panel cointegration tests to test for the existence of a long-run relationship between the black market and the official exchange rate in six emerging countries (i.e., Iran, India, Indonesia, Korea, Pakistan, and Thailand). Moreover, we impose the unity (proportionality) restriction on the cointegrating coefficient, consistently with portfolio-balance models (see, e.g., Dornbusch et al, 1983), and test its validity by carrying out a Wald test in a panel context. Finally, we investigate the short-run dynamics by estimating impulse response functions using bootstrap methods.

The layout of the paper is the following. Section 2 outlines the econometric methodology. Section 3 describes the data and presents the empirical results. Section 4 summarises the main findings and provides an economic interpretation.

\section{Econometric Methodology}

Let $s_{i t}$ and $s_{i t}^{*}$ be the $\log$ of the black market and of the official exchange rate, respectively, in country $i$. To take into account heterogeneity, we apply the McCoskey and Kao (1998) panel cointegration test by specifying the following DOLS (Dynamic OLS - see Stock and Watson, 1993) regression equation:

$$
s_{i t}=\alpha_{i}+\beta s_{i t}^{*} \sum_{j=-k}^{k} \phi_{j} \Delta s_{i, t-1}^{*}+u_{i t}
$$

$$
\mathrm{i}=1, \ldots \mathrm{N}, \mathrm{k}_{\mathrm{i}}=\text { leads and lags of } \Delta \mathrm{s}^{*}{ }_{\mathrm{i}}
$$

The number of leads and lags in equation (1) is chosen with the Akaike criterion. In the presence of significant autocorrelation, even with high orders of leads and lags, one should instead employ the DGLS (Dynamic Generalised Least Squares - see 
McCoskey and Kao, 1998) estimation method, together with the Newey and West (1994) HAC (heteroscedasticity and autocorrelation consistent) covariance estimator, as we do below (see Section 3).

The method introduced by McCoskey and Kao (1998) involves a residualbased Lagrange Multiplier test for the null hypothesis of cointegration in panel data. This test is a panel version of the Harris and Inder (1994) cointegration test for time series. McCoskey and Kao (1998) show that the standardised version of the LM statistic is given by:

$$
L M^{*}=\frac{\left[\sqrt{N}\left(L M-u_{v}\right)\right]}{\sigma_{v}} \Rightarrow N(0,1)
$$

where $u_{v}$ and $\sigma_{v}$ are obtained by Monte Carlo simulation methods (see Table 1, McCoskey and Kao, 1998).

We also analyse the short-run dynamic adjustment of exchange rates to external shocks by estimating impulse response functions Let $S_{t}=\left[s_{t}, s_{t}^{*}\right]^{\prime}$ be a discrete time real valued vector stochastic process, and assume it follows the following Vector Autoregressive model of order $k ; \operatorname{VAR}(k)$ :

$$
S_{t}=\Pi_{0}+\Pi_{1} S_{t-1}+\Pi_{2} S_{t-2}+\ldots+\Pi_{k} S_{t-k}+\mathrm{B} u_{t} \quad t=1,2 \ldots
$$

where $u_{t}$ is a $p \times 1$ vector of error terms having a martingale specification with covariance matrix $\Omega$.

In a more compact form (3) can be written as follows:

$$
\Pi(L) S_{t}=\mathrm{B} u_{t}
$$

where $\Pi(L) \equiv \Pi_{0}-\Pi_{1} L-\Pi_{2} L^{2}-\ldots-\Pi_{p} L^{p}$, with $L$ being a lag operator.

A Vector Moving Average (VMA) representation of (3) is:

$$
S_{t}=C(L) u_{t}
$$

where $C(L)=\Pi(L)^{-1} ; C(L)=\mathrm{I}+C_{1}(L)+C_{2} L^{2} \ldots$, and $C(L)$ is a polynomial matrix generally of infinite order.

Let $\phi_{k l, i}$ be the response of the variable $k$ to a standard deviation shock on the variable $l, i$ periods ahead, and define as $\varphi=\left[\Pi_{1}, \Pi_{2}, \ldots, \Pi_{p}\right]^{\prime}$, a vector that stacks the parameters of the system in (3). Impulse responses are obtained by inverting the polynomial (3), therefore $\phi_{k l, i}$ is a non-linear function of $\varphi^{\prime}$ such that $\phi_{k l, i}(\varphi)$. Because of its non-linearity, in small samples $\phi_{k l, i}$ can be biased, with the bias increasing with the length of the horizon. For this reason, confidence intervals should also be constructed. Different methods have been suggested. In this paper we follow Kilian (1999) and adopt a residual-based resampling method (i.e. a semi-parametric one). 


\section{Empirical Analysis}

We use monthly data on black market and official exchange rates for six emerging market economies, namely Iran, India, Indonesia, Korea, Pakistan and Thailand, for the period 1973M1-1998M1. The former series are obtained from Pick's World Currency Yearbook (various issues). In this respect, our study differs from earlier ones focusing on individual countries (see, e.g., Booth and Mustafa, 1991), or using annual data covering a shorter period (see, e.g., Bahmani-Oskooee et al, 2002)

Table 1 shows the average black-market premium for the six exchange rates being analysed. As can be seen, it is positive for all countries and sizeable in the case of Iran and Indonesia, whilst it is rather small for Thailand.

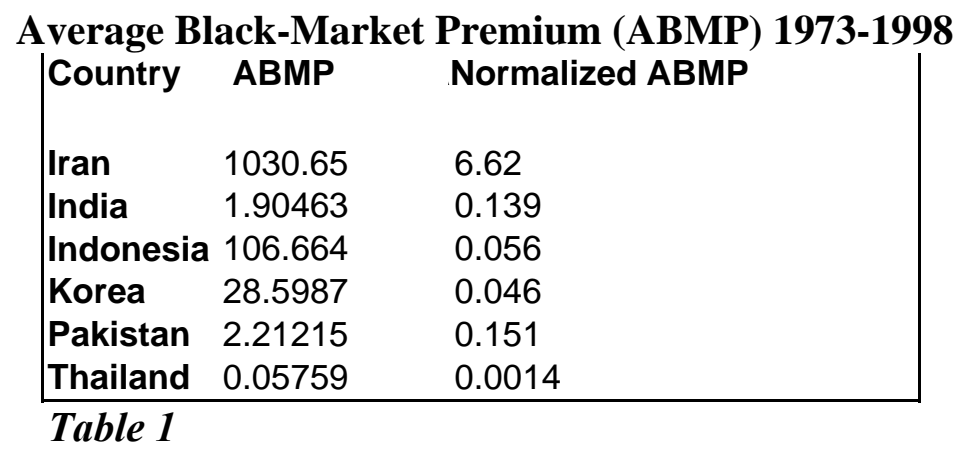

Note: the Normalized ABMP has been obtained by dividing the black market premium by the official exchange rate.

We then apply panel unit root tests to test for stationarity of the black market and official exchange rates. Taylor and Sarno (1998) propose a panel unit root test for the joint null hypothesis of nonstationarity The test is based on the Johansen maximum likelihood method for multivariate cointegration, where the null hypothesis is that at least one of the series in the panel has a unit root, $\mathrm{H}_{0}$ : rank $(\Pi)<\mathrm{N}$. The null is rejected if and only if all the series in the panel are stationary processes, i.e. $\mathrm{H}_{1}: \operatorname{rank}(\Pi)=\mathrm{N}$, where the matrix $\Pi$ denotes the long-run solution of the VAR system for $\mathrm{N}$ variables. This is equivalent to testing the null hypothesis that the smallest eigenvalue of $\Pi, \lambda_{\min }$, is non-zero, which is done using Johansen's likelihood ratio statistic (JLR),

$$
J L R=-T \ln \left(1-\lambda_{\min }\right)
$$

Taylor and Sarno (1998) show that the $J L R$ statistic has a limiting $\chi^{2}(1)$ distribution under the null hypothesis. The results of the JLR test are reported in Table 2, and confirm that both types of exchange rates are I(1) processes, as usually found in the empirical literature. 


\section{Taylor and Sarno (1998) JLR Panel Unit Root Test}

\begin{tabular}{|l|l|}
\hline & JLR statistic \\
\hline$s_{t}$ & 0.110556 \\
\hline$s_{t}^{*}$ & 0.123574 \\
\hline
\end{tabular}

Table 2

Note: The 5\% critical value is 3.9712 (Taylor and Sarno, 1998, Table 3).

Next, we test for cointegration between the two exchange rates. As pointed out by Booth and Mustafa (1991), the existence of cointegration is inconsistent with the efficient market hypothesis, which implies that past information on the exchange rate cannot be exploited to forecast future values: a feedback from one market to the other would constitute evidence of weak-form informational inefficiency in the black market.

McCoskey and Kao (1998) Panel Cointegration Test

\begin{tabular}{|lllll|}
\hline Country & Leads/Lags & $\boldsymbol{A R}(\boldsymbol{\rho})$ & $\boldsymbol{P r}[\mathbf{F a}]$ & $\begin{array}{l}\text { Harris and Inder } \\
\text { CointegrationTest }\end{array}$ \\
Iran & 1 & 1 & 12.15 & 0.0787 \\
India & 2 & 1 & 10.39 & 0.1286 \\
Indonesia & 7 & 2 & 6.77 & 0.1506 \\
Korea & 8 & 2 & 15.58 & 0.2921 \\
Pakistan & 1 & 1 & 8.88 & 0.1313 \\
Thailand & 7 & 1 & 14.35 & 0.3689 \\
McCoskey-Kao panel test & & & $\mathbf{0 . 5 6}$ \\
(LM & & & \\
CV-5\% & & & & $\mathbf{1 . 6 4}$ \\
\hline
\end{tabular}

Table 3

Note: (a) The critical values for the Harris and Inder cointegration test (for time series with 1 regressor) are: $1 \%=0.5497 ; 5 \%=0.3202$ (Harris and Inder, 1994, Table 1). (b) The $\mathrm{LM}^{*}$ test is one-sided with a critical value of 1.64 (i.e. $\mathrm{LM}^{*}>1.64$ implies rejection of the null hypothesis of cointegration).

(c) $\operatorname{Pr}[\mathrm{Fa}]$ is the probability value of an $\mathrm{F}_{0}$ version of the Breusch-Godfrey test for $9^{\text {th }}$ order autocorrelation. $A R(\rho)$ denotes the order of the autoregressive scheme employed in the model.

Table 3 reports two cointegration tests, specifically the McCoskey and Kao (1998) panel cointegration test, and the univariate cointegration tests due to Harris and Inder (1994), which is a time series version of it. Looking at the individual cointegration tests, we note that there is evidence of cointegration in all countries. The panel cointegration test also confirms that there exists a long-run relationship between the two exchange rates, and that therefore the black market cannot be characterised as efficient. 
Table 4 presents DGLS estimates of the cointegrating vector. As can be seen, all the coefficients are statistically significant (at least at the $10 \%$ confidence level), with the exception of the intercept for Thailand.

A useful framework to provide an economic interpretation of the relationship between the two types of exchange rates is the portfolio-balance class of models (see, e.g., Dornbusch et al, 1983). This asserts that asset market conditions determine the black market rate, and the current account affects it through the stock of black-market foreign currency. Consequently, there is a proportional equilibrium relationship between the two rates, which implies that the long-run parameter $\beta$ should be equal to unity, resulting in a constant black-market premium. In the short run, the black market rate overshoots, as the supply of foreign currency is fixed, i.e. the premium falls as a result of an unanticipated devaluation; however, in the long run changes in the black market rate affect the current account and the stock of foreign currency, which eventually results in a proportional change in the black market rate, with the premium reverting to its long-run value. We test for this long-run restriction (i.e. the proportionality restriction) by means of a Wald test (see Table 4).

DGLS Estimates (Equation 1)

\begin{tabular}{|llll|}
\hline $\begin{array}{l}\text { Country } \\
\text { Iran }\end{array}$ & $\alpha$ & $\beta$ & $\begin{array}{l}\beta=\mathbf{1} \\
{\left[\chi^{2}(\mathbf{1})\right]}\end{array}$ \\
& 13.29 & 0.02 & \\
India & {$[1.13]$} & {$[2.06]$} & 20.50 \\
& 0.312 & 0.93 & \\
Indonesia & {$[7.54]$} & {$[65.7]$} & 19.45 \\
& -0.30 & 1.01 & \\
Korea & {$[-1.74]$} & {$[40.57]$} & 3.96 \\
Pakistan & 1.16 & 0.83 & \\
& {$[2.12]$} & {$[9.84]$} & 4.19 \\
Thailand & 0.463 & 0.89 & \\
PLR & {$[3.62]$} & {$[20.28]$} & 6.91 \\
CV-1\% & -0.120 & 1.03 & \\
CV-5\% & {$[-0.87]$} & {$[23.37]$} & 0.76 \\
\hline
\end{tabular}

Table 4

Note: Numbers in parentheses below the regression coefficients are t-values. $\chi^{2}(1)$ is the Wald test for the proportionality restriction, $\mathrm{H}_{0}: \beta=1(5 \% \mathrm{CV}=3.84)$. PLR is the corresponding panel likelihood ratio statistic that follows a $\chi^{2}(\mathrm{v})$ distribution with $\mathrm{N}(=6)$ d.f .

As in Cerrato and Sarantis (2003), we also extend this test to a panel context. The null hypothesis of a valid restriction is accepted in the case of Thailand and marginally rejected for Indonesia, whilst it is strongly rejected in all the other cases. The panel test confirms that the proportionality restriction cannot be accepted for the six countries under investigation. This result would suggest that foreign exchange controls could have a long-run impact, with the black market rate deviating from the official one. By contrast, Bahmani-Oskooee et al (2002) state in their study that in the long run full adjustment takes place. Note, however, that these authors base their claim simply on point estimates (close to one) of the long-run slope coefficient, 
without carrying out any statistical tests of the relevant restriction, which, instead, we do. ${ }^{1}$

On the basis of these findings, we can conclude that black market and official exchange rates are linked in the long run (which casts doubt on their informational efficiency), though the panel evidence also indicates that the black-market premium is unlikely to disappear even in the long run, and hence foreign exchange policies might be effective.

Finally, we investigate the short-run dynamic adjustment between the two types of exchange rates. Figures 1-6 show impulse responses to a unit standard deviation shock to either exchange rate. The empirical results appear to confirm the positive significant impact of the official exchange rate on the black market exchange rate. Furthermore, they are consistent with the sign of the $\beta$-coefficient estimated by DGLS.

We also examine the response of each exchange rate to shocks to the same market. These show that both the official and the black market exchange rates are highly persistent processes ${ }^{2}$. However, in general, the speed of response to a unit standard deviation shock seems to be higher for the black market exchange rate compared to the official one.

On the whole, we observe the short-run overshooting predicted by portfoliobalance models. However, we also find that, even after forty months, the effects of shocks have not died away, which is inconsistent with the long-run full adjustment implied by this class of models. ${ }^{3}$ It would appear, therefore, that the long-run blackmarket premium is not constant, or, at least, that deviations from the long-run equilibrium are long-lived, with long memory characterising these processes (see Granger and Joyeux, 1980).

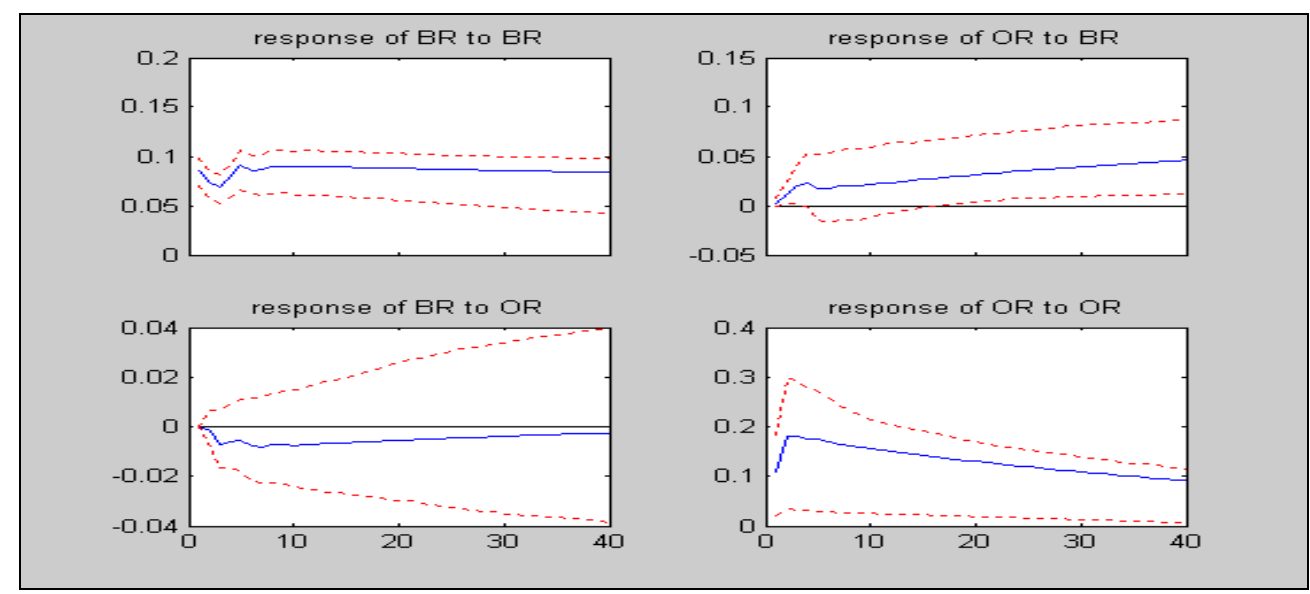

Figure 1: Iran; BR and OR are respectively black market and official market exchange rates.

\footnotetext{
${ }^{1}$ Some single-country studies test formally the long-run proportionality restriction, and cannot reject it (see, e.g., Kouretas and Zarangas, 2001).

${ }^{2}$ We tested for stationarity of the individual exchange rates and found that, with the exception of Korea, they were all non-stationary. This might explain their persistence as shown by the impulse response function.

${ }^{3}$ This result is consistent with Cerrato and Sarantis (2004), who found point estimates of half-lives deviation of the exchange rate from PPP ranging, for some of these countries, between 0.22 years and infinity, while the upper bounds of the confidence intervals were in all cases infinite.
} 


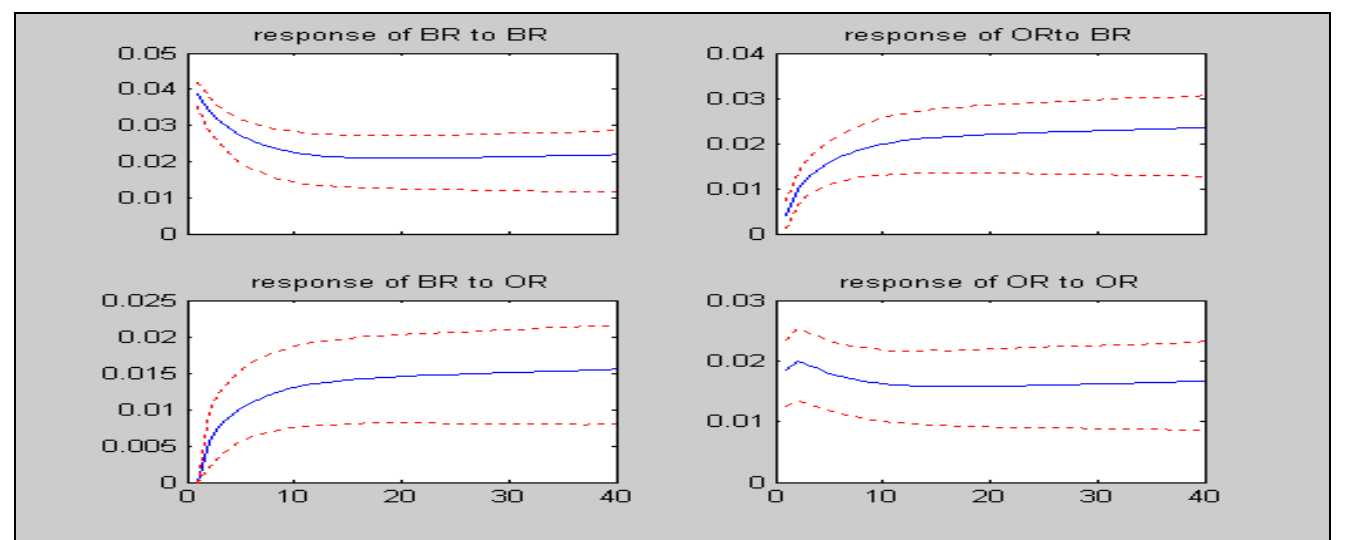

Figure 2: India; $B R$ and $O R$ are respectively black market and official market exchange rates.

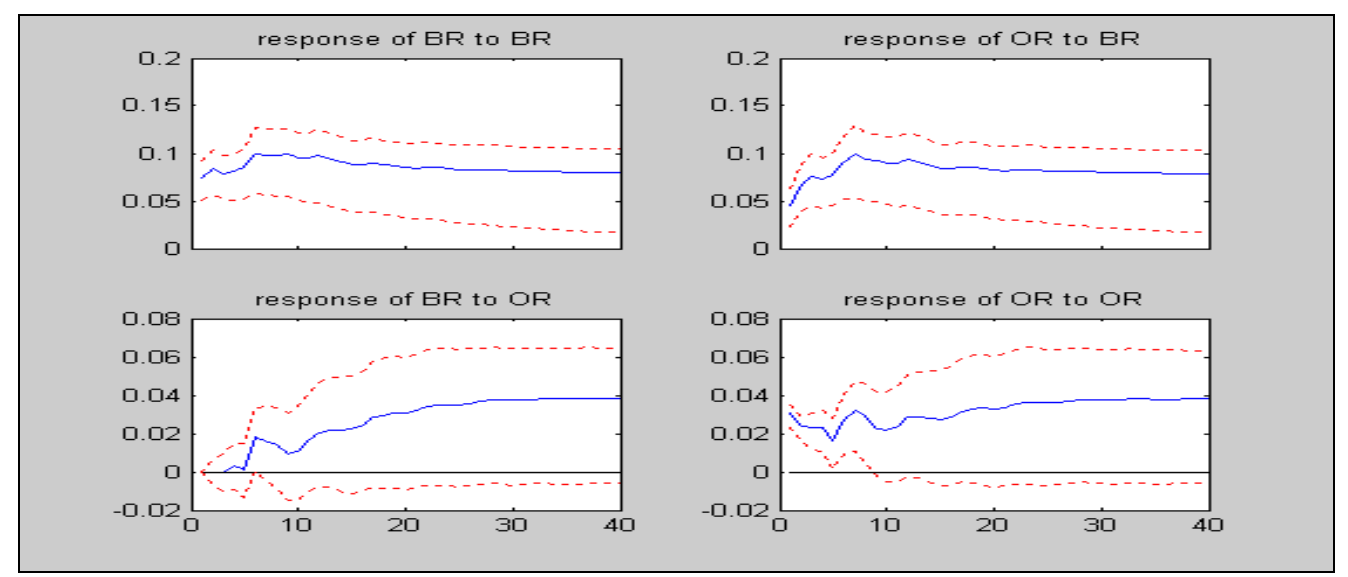

Figure 3: Indonesia; $B R$ and $O R$ are respectively black market and official market exchange rates.

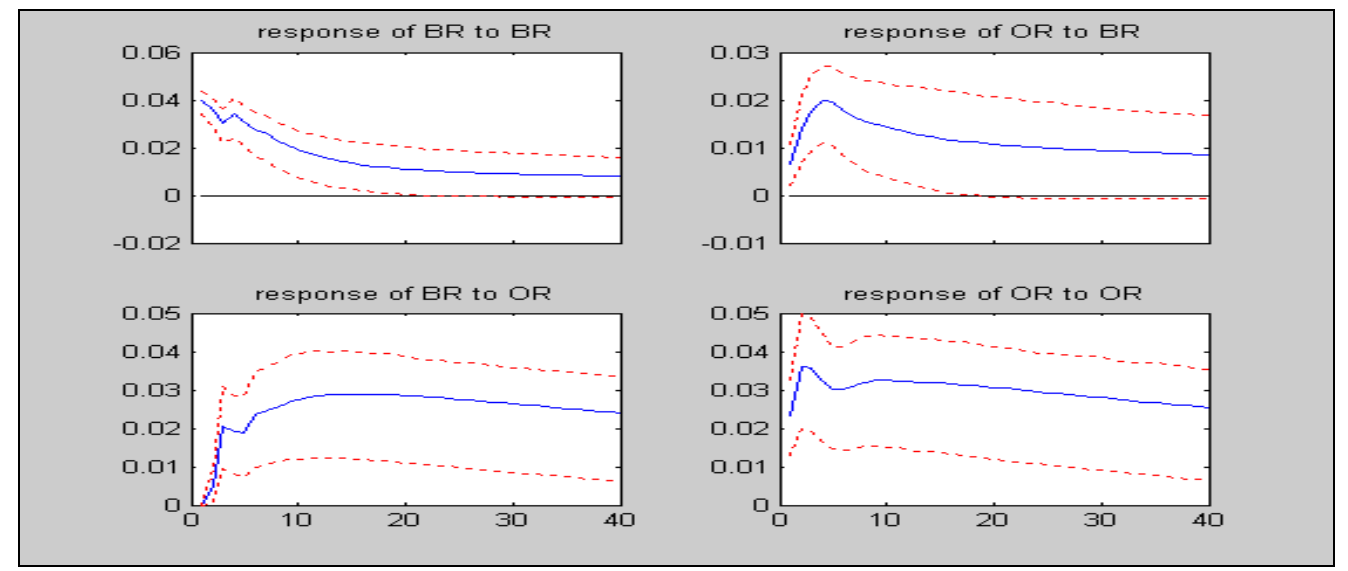

Figure 4: Korea; BR and OR are respectively black market and official market exchange rates. 


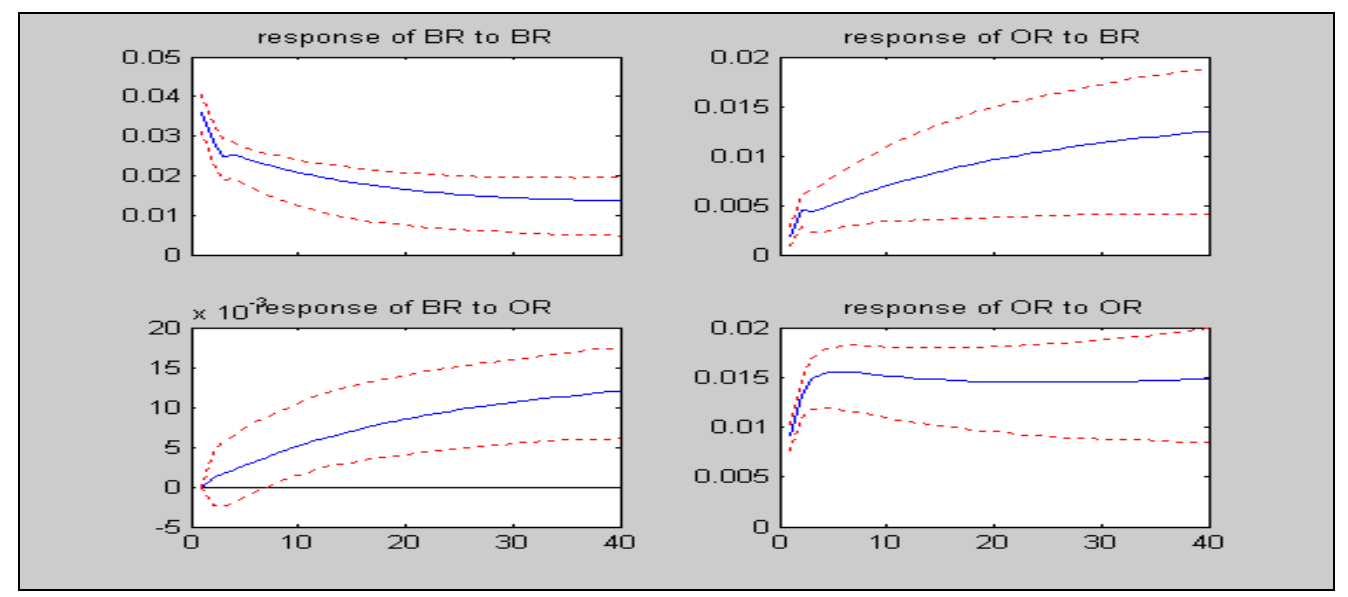

Figure 5: Pakistan; BR and OR are respectively black market and official market exchange rates.

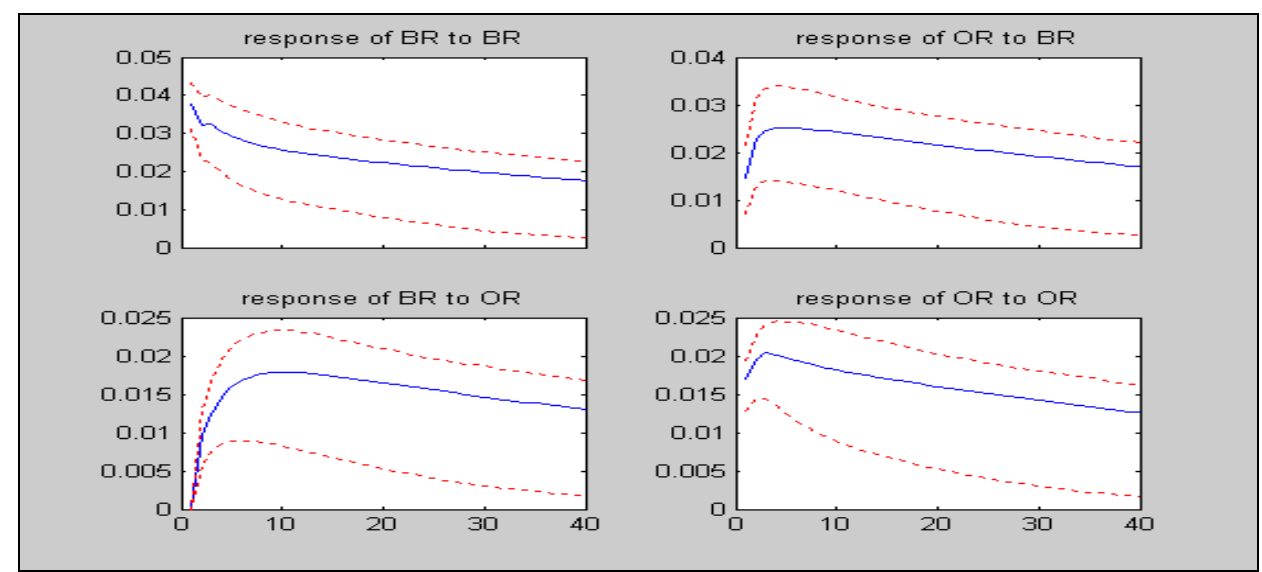

Figure 6: Thailand; $B R$ and $O R$ are respectively black market and official market exchange rates.

\section{Conclusions}

This paper provides further empirical evidence on the relationship between black market and official exchange rates in six emerging economies (Iran, India, Indonesia, Korea, Pakistan, and Thailand). First, it applies both time series techniques and heterogeneous panel methods to test for the existence of a long-run relation between these two types of exchange rates. Second, it tests formally the validity of the proportionality restriction implying a constant black-market premium (unlike other studies, such as Bahmani-Oskooee et al, 2002, only reporting point estimates). Third, in addition to the long-run equilibrium, it also analyses the short-run dynamic responses of both markets to shocks. Our empirical analysis suggests that black market and official rates are linked in the long run. This points to weak-form informational inefficiency (see Booth and Mustafa, 1991), which might reflect the existence of transaction costs and/or foreign exchange controls. However, unlike other authors (e.g., Kouretas and Zarangas, 2001), we also find that the proportionality restriction, which is an essential feature of portfolio-balance models (see Dornbusch et al, 1983), is rejected, indicating that the adjustment towards equilibrium in response to short-run shocks is incomplete. Partial reversion to the long-run equilibrium (or possibly the presence of long-memory features) is confirmed by the short-run analysis, showing that the initial overshooting does not totally fade away.

These results have important implication for both fund managers and policymakers. Market inefficiency (and hence the possibility of international arbitrage) 
suggests that the former can reduce exchange rate risk knowing that fluctuations in the black market rate signal corresponding adjustments in the official rate However, the exchange rate risk cannot be eliminated altogether, as full adjustment does not take place (or is extremely slow), and a widening gap between the two exchange rates is only partially closed (at least over a relevant investment horizon). Permanent (or long-lived) deviations from equilibrium also imply that monetary authorities can effectively pursue their policy objectives by imposing foreign exchange or direct controls (see Kiguel and O'Connell, 1995), not having to adjust the official rate to the market-determined parallel one in order to close the gap between the two (at least for a considerable time) - a crucial policy implication. This is in stark contrast to the study of Bahmani-Oskooee et al (2002), where proportionality is not formally tested.

\section{References}

Bahmani-Oskooee, M., Miteza, I. and Nasir, A.B.M. (2002), "The long-run relation between black market and official exchange rates: evidence from panel cointegration", Economics Letters, 76, 397-404.

Booth, G.G. and C. Mustafa (1991), "Long-run dynamics of black and official exchange rates", Journal of International Money and Finance, 10, 392-405.

Cerrato, M., and N. Sarantis (2004), "The Purchasing Power Parity persistence puzzle: evidence from black market real exchange rates", D.P. no.04-02, Centre for International Capital Markets, London Metropolitan University.

Cerrato, M., and N. Sarantis (2003), "Does the Purchasing Power Parity hold in emerging markets? Evidence from a panel of black market exchange rates", D.P. no. 03-04, Centre for International Capital Markets, London Metropolitan University.

Dornbusch, R., Dantas, D.V., Pechman, C., Rocha, R.R. and D. Simoes (1983), "The black market for dollars in Brazil", Quarterly Journal of Economics, 98, $25-40$.

Granger, C.W.J. and R. Joyeux (1980), "An introduction to long memory time series models and fractional differencing", Journal of Time Series Analysis, 1, 15-29.

Harris, D. and B. Inder (1994), "A test of the null hypothesis of cointegration", in C.P. Hargreaves (ed.), Nonstationary Time Series Analysis and Cointegration, 133152, Oxford University Press, Oxford.

Kiguel, M.A. and O' Connell, S.A. (1995), "Parallel exchange rates in developing countries", The World Bank Research Observer, 10, 21-52.

Kilian, L. (1999), "Exchange rates and monetary Fundamentals: what do we learn from long-horizon regressions?", Journal of Applied Econometrics, 14, 5, 1999, 491-510.

Kouretas, G. and L.P. Zarangas (2001), "Black and official exchange rates in Greece: an analysis of their long-run dynamics", Journal of Multinational Financial Management, 11, 295-314.

McCoskey, S., and Kao, C. (1998), "A residual-based test of the null of cointegration in panel data", Econometric Reviews, 17, 57-84.

Newey, W.K. and K.D. West (1994), "Automatic lag selection in covariance matrix estimation", Review of Economic Studies, 61, 4, 631-653.

Stock, J.H. and M.W. Watson (1993), "A simple estimator of cointegrating vectors in higher-order integrated systems", Econometrica, 61, 783-820.

Taylor, M.P and Sarno, L. (1998), " The behaviour of real exchange rates during the post Bretton Woods period", Journal of International Economics, 46, 281312. 